\title{
TÍNH TOÁN TỶ LỆ PHÂN CHIA LƯU LƯợNG ỨNG VỚI CÁC CẤP LŨ TẠI NGÃ BA BẢY YỂN TRỀN HỆ THỐNG SÔNG KONE - HÀ THANH TİNH BİNH ĐỊNH
}

\author{
Trần Kim Châu ${ }^{1}$, Đỗ Anh Đức ${ }^{2}$, Bùi Mạnh Bằng²
}

Tóm tắt: Việc phân chia lưu lượng tại các ngã ba sông là một vấn đề phức tạp, nó đóng vai trò quyết định đến chế độ thủy lực của hệ thống sông cũng nhu các tiểu chuẩn phòng chống lũ ở hạ lư các nhánh sông. Trong nghiên cứu này, các tác giả sử dụng các mô hình thủy lực nhà̀m tính toán tỷ lệ phân chia lưu luoong vào các nhánh sông của hệ thống sông Kone - Hà Thanh tại ngã ba Bảy Yển úng với các cấp lư lượng lũ. Nghiên cứu cho thấy lượng nước chuyển qua các nhánh sông có xu thế không đồng nhất khi lũ tăng. Đối với trận lũ lớn, tổng lương nước chuyển qua các nhánh sông chỉ khoảng 72\% lựng nước đến ngã ba. Trong đó 40\% chuyển qua nhánh chính sông Kone. Lương nước qua các nhánh Đập Đá và Gò Chàm lần lượt là $18 \%$ và $14 \%$. Những giá trị này là co sở nhằm xác định các tiểu chuẩn phòng lũ khác nhau cho các công trình nằm ở ha du.

Từ khóa: Kone - Hà Thanh, phân chia lưu lương, Mike Flood, Bảy Yển.

Ban Biên tập nhận bài: 12/6/2019 Ngày phản biện xong: 15/7/2019 Ngày đăng bài: 25/11/2019

\section{Mở đầu}

Lưu vực sông Kone - Hà Thanh nằm chủ yếu trên địa giới hành chính tỉnh Bình Định. Đây là lưu vực sông có địa hình phân bố phức tạp không có vùng chuyển tiếp giữa vùng núi cao và đồng bằng. Cụ thể, thượng nguồn của sông dốc đặc trưng cho sông miền núi, đến ngã ba Bảy Yển, tại đây độ dốc lòng dẫn giảm mạnh và hình thành các phân lưu chia lưu lượng vào các nhánh sông có tên là Gò Chám, Đập Đá. Sau đó các nhánh sông phân, nhập tạo thành mạng lưới sông ngòi chằng chít trước khi chuyển tiếp qua Đầm Thị Nại và đổ ra biển. Chính vì những đặc trưng này làm cho chế độ thủy lực trên sông chính và các phân lưu có quan hệ mật thiết với nhau, phần nào gây khó khăn trong việc kiểm soát lũ, công tác phòng chống thiên tai.

Theo Quyết định số 1588/QĐ-TTg [1] ngày 24/10/2012 của Thủ tướng Chính phủ quy định tiêu chuẩn phòng chống lũ vùng hạ lưu sông Kone là chống lũ chính vụ 5\% cho thành phố Quy Nhơn và chống lũ sớm, lũ muộn 10\% phục vụ sản xuất. Vấn đề đặt ra trong những trường

${ }^{1}$ Trường Đại học Thuỷ Lợi

${ }^{2}$ Viện Khoa Họ Lợi Việt Nam

Email:kimchau_hwru@tlu.edu.vn hợp lũ lớn hơn trận lũ tương đương lũ sớm, lũ muộn $10 \%$, sẽ xảy ra hiện tượng tràn bờ sông tại một số vị trí không có công trình bảo vệ hoặc địa hình thấp. Điều này sẽ gây khó khăn trong việc xác định tiêu chuẩn phòng chống lũ cho các khu vực, các công trình khác nhau ở khu vực hạ du.

Từ những đòi hỏi này cần phải xác định tỷ lệ phân chia lưu lượng tại nhánh các nhánh sông cho các cấp độ lũ khác nhau làm cơ sở cho việc đề xuất các giải pháp phòng chống lũ cho vùng hạ du.

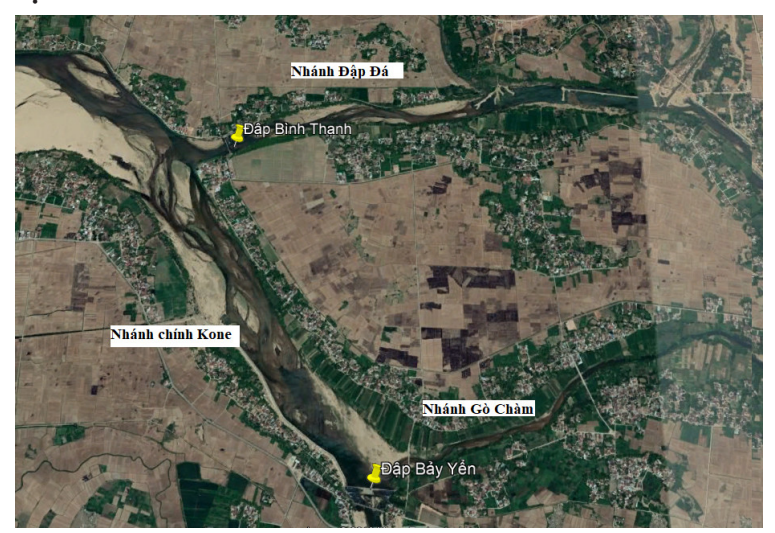

Hình 1. So đồ̀ vùng nghiên cúu

2. Phương pháp nghiên cứu và tài liệu thu thập

Để tiến hành đánh giá chế độ thủy lực của 
khu vực nghiên cứu, các tác giả tiến hành tiến hành xây dựng mô hình kết hợp $1 \& 2$ chiều Mike Flood mô phỏng cả hệ thống mạng lưới sông Kone Hà Thanh. Đây là bộ công cụ được DHI phát triển, rất thích hợp tính toán cho các khu vực sông có hiện tượng tràn bờ như ở khu vực nghiên cứu $[2,3]$. Sở dĩ phải thiết lập cả hệ thống sông vì đặc điểm của khu vưc này rất phức tạp. Các sông trong hệ thống được đan nối với nhau một cách chằng chịt. Điều này làm chế độ thủy lực của hệ thống sông có mối liên hệ chặt chẽ với nhau theo không gian. Các yếu tố động lực tại một vị trí trên sông này có thể ảnh hưởng đến yếu tố động lực của nhiều vị trí trên các sông khác.

Hạ lưu hệ thống sông Kone - Hà Thanh gồm có 5 sông chính chia thành 14 nhánh sông. Từ dữ liệu địa hình, mặt cắt ngang, trắc dọc sông được đo đạc trên hệ thống sông Kone-Hà Thanh và các sông nhánh, tiến hành thiết lập sơ đồ thủy lực 1 chiều mạng lưới sông, suối. Số lượng các mặt cắt trên dòng chính cũng như các nhánh được thống kê chi tiết ở Bảng 1.

Biên trên là đường quá trình lưu lượng xả ra từ các hồ Định Bình, Thuận Ninh, Núi Một, Núi Thơm và lưu lượng tại vị trị trạm thủy văn Hà Thanh. Biên dưới là quá trình mực nước triều tại trạm thủy văn Quy Nhơn. Biên nhập lưu khu giữa được được kế thừa từ kết quả tính toán từ mô hình mưa rào dòng chảy trong nghiên cứu của Đỗ Anh Đức và cs (2018) [4]. Các khu giữa có nguồn bổ sung dòng chảy đáng kể cho hệ thống sông.

Bảng 1. Thống kê các nhánh sông trong mô hình

\begin{tabular}{|c|c|c|c|}
\hline Tên sông & Đoạn & $\begin{array}{l}\text { Chiều dài } \\
(\mathrm{m})\end{array}$ & Số mặt cắt \\
\hline Kone & Từ hồ Định Bình đến đầm Thị Nại & 83513 & 84 \\
\hline Núi Một & Từ xã Nhơn Tân đến Nhơn Hòa & 16931 & 56 \\
\hline Đập Đá & Từ xã Nhơn Mỹ đến đầm Thị Nại & 32714 & 47 \\
\hline Gò Chàm & Từ xã Nhơn Khánh đến xã Phước Hòa & 20602 & 23 \\
\hline Thuận Ninh & Từ xã Bình Tân đến xã Bình Hòa & 13793 & 12 \\
\hline Cây My & Từ xã Phước Hiệp đến xã Phước Hòa & 7299 & 10 \\
\hline Tân An & Từ xã Phước Hiệp đến đầm Thị Nại & 11482 & 9 \\
\hline Thạnh Hòa & Từ xã Nhơn Hòa đến xã Phước Nghĩa & 10778 & 20 \\
\hline Trườnng Úc & Từ xã Diêu Trì đến đầm Thị Nại & 12937 & 26 \\
\hline Hà Thanh & Từ xã Phước Thành đến đầm Thị Nại & 20626 & 21 \\
\hline Núi Thơm & Từ xã Phước Thành đến xã Diêu Trì & 10849 & 14 \\
\hline Nhanh1 & Từ xã Diêu Trì đến xã Nhơn Bình & 8561 & 14 \\
\hline Nhanh2 & Từ xã Nhơn Phú đến đầm Thị Nại & 7620 & 10 \\
\hline Đầm Thị Nại & & 15864 & 8 \\
\hline Quanh Vật & Từ xã Nhơn Mỹ đến xã Cát Nhơn & 19398 & 10 \\
\hline Văn Lang & Từ xã Nhơn An đến xã Cát Chánh & 15822 & 9 \\
\hline Nhánh Kone & Một nhánh nhỏ của sông Kone & 5227 & 2 \\
\hline NhanhC & Từ xã Diêu Trì đến đầm Thị Nại & 9155 & 13 \\
\hline Tránh & & 955 & 6 \\
\hline
\end{tabular}


Trong mô hình hệ thống đường giao thông, đê sông, các đập dâng, các cống qua đường cũng được các tác giả mô phỏng để đảm bảo đúng với hiện trạng của vùng nghiên cứu.

Phạm vi miền tính của mô hình là từ hạ lưu hồ chứa Định Bình xuống đến đầm Thị Nại, địa hình khu vực tính toán tương đối bằng phẳng và mạng lưới sông ngòi kênh rạch chằng chịt nên nghiên cứu sử dụng lưới tam giác để tính toán. Để đảm bảo độ chính xác cho quá trình mô phỏng dòng chảy lũ khu vực nghiên cứu và lưới này không quá rộng và tiết kiệm thời gian tính toán, dự án sử dụng lưới ô lưới tam giác với diện tích mỗi ô lưới tối đa là $6000 \mathrm{~m}^{2}$ tương đương mỗi cạnh tam giác là khoảng $117 \mathrm{~m}$. Kết quả tạo lưới trong mô hình cho thấy khu vực tính toán được chia thành 192748 ô lưới.

Trong nghiên cứu này, các tác giả sử dụng 2 mô hình lũ điển hình 2013 và 2016 lần lượt là lũ chính vụ và lũ muộn đã xảy ra trên lưu vực để thu phóng cho lũ các tần suất lũ chính vụ và lũ muộn. Số liệu tính toán mực nước tại một số trạm đo và tại các đập dâng được so sánh với số liệu đo đạc để đảm bảo độ chính xác trong việc mô phong chế độ thủy động lực học hệ thống sông Kone - Hà Thanh.

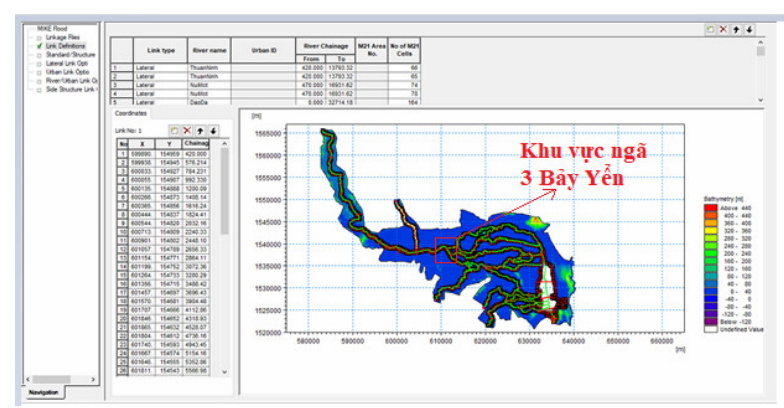

Hình 2. Mô hình thủy lục Mike Flood

Bảng 2. Các kịch bản tính toán

\begin{tabular}{|c|c|}
\hline KB & Mô tả \\
\hline KB 01 & $\begin{array}{l}\text { Mô phỏng lũ sớm, muộn tần suất } 10 \% \text { ứng } \\
\text { với điều kiện hiện trạng của khu vực }\end{array}$ \\
\hline KB 02 & $\begin{array}{l}\text { Mô phỏng lũ sớm, muộn tần suất 5\% ứng } \\
\text { với điều kiện hiện trạng của khu vực }\end{array}$ \\
\hline BB 03 & $\begin{array}{l}\text { Mô phỏng lũ chính vụ tần suất } 10 \% \text { ứng } \\
\text { với điều kiện hiện trạng của khu vực }\end{array}$ \\
\hline KB 04 & $\begin{array}{l}\text { Mô phỏng lũ chính vụ tần suất } 5 \% \text { ứng với } \\
\text { điều kiện hiện trạng của khu vực }\end{array}$ \\
\hline
\end{tabular}

\section{Kết quả}

Nghiên cứu đã mô phỏng thành công hệ thống sông Kone -Hà Thanh bằng mô hình thủy lực Mike Flood. Kết quả mô phỏng sát với thực tế và được thể hiện ở hình vẽ và bảng biểu dưới đây.

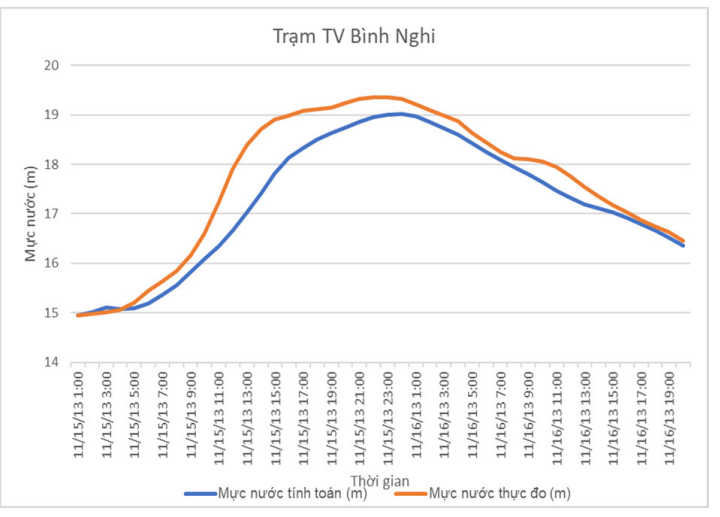

Hình 3. Đuờng quá trình mưc nước tính toán và thưc đo trạm Bình Nghi năm 2013

Bảng 3. Kết quả hiệu chỉnh mô hình

\begin{tabular}{lcccc}
\hline \multirow{2}{*}{$\begin{array}{c}\text { Trạm } / \\
\text { Đập dâng }\end{array}$} & \multicolumn{3}{c}{ Cao trình mực nước $(\mathrm{m})$} & \\
\cline { 2 - 4 } & Lũ 2013 & Tính toán & Chênh lệch & Nash \\
\hline Bình Tường & 19.35 & 19.02 & -0.33 & 0.87 \\
Thạnh Hòa & 9.68 & 9.20 & -0.48 & 0.90 \\
Diêu Trì & 6.56 & 6.43 & -0.13 & 0.91 \\
Bình Thạnh & 15.3 & 15.35 & 0.05 & \\
Bảy Yển & 14.8 & 14.93 & 0.13 & \\
\hline
\end{tabular}

Dựa trên bộ thông số mô hình thủy lực kiểm chứng, tiến hành tính toán các kịch bản như trong bảng 2. Cở sở lựa chọn các kịch bản tính toán dựa trên các tiêu chuẩn chống lũ của các khu dân cư và các công trình phía hạ lưu. Dựa trên kế quả mô hình để tính toán tỷ lệ phần chia lưu lượng tại các nhánh sông thuộc ngã ba Bảy Yển.

Từ kết quả hiệu chỉnh kiểm định của mô hình cho thấy mô hình mô phỏng khá tốt với thực tế, do vậy nhóm tác giả áp dụng mô hình này để mô phỏng cho các kịch bản tính toán.

Kết quả tính toán tỷ lệ phân chia lưu lượng phân được chia từ sông Kone vào các nhánh sông Gò Chàm, Đập Đá và còn lại trong ở sông Kone thể hiện ở bảng 4 . Trong bảng này lưu lượng đỉnh lũ vào cách nhánh sông được tính tỷ lệ với lưu lượng đỉnh lũ tại vị trí trước phân lưu 
của sông Kone và nhánh Đập Đá, giá trị được ghi số trong ngoặc). Trong các kịch bản tính toán nhận thấy hiện trạng lòng dẫn các sông chính đảm bảo thoát lũ sớm, muộn $10 \%$ (Hình 5). Trong trường hợp này đã xuất hiện vùng ngập ở hạ du, nhưng chỉ ở gần Đầm Thị Nại. Hiện tượng ngập này là do ảnh hưởng của thủy triều, không phải do lũ trong sông.

Đối với lũ sớm, lũ muộn tần suất $5 \%$, chỉ còn lòng dẫn nhánh Đập Đá tải được lượng lũ này. Bắt đầu có hiện tượng tràn bờ ở nhánh Gò Chàm và trên nhánh chính sông Kone như hình 6 . Tuy nhiên lượng tràn bờ không lớn khi tổng lượng chảy qua 3 nhánh sông cũng gần bẳng $(98 \%)$ lưu lượng trước phần lưu vào ngã ba. Dựa trên kết quả tính toán kịch bản 02 ở bảng 4 , nhận thấy đây là những giá trị ngưỡng để xác định khả năng tải của lòng sông ứng với điều kiện hiện trạng. Những giá trị này sẽ là cơ sở cho việc xác định hành lang thoát lũ cho mỗi nhánh sông.

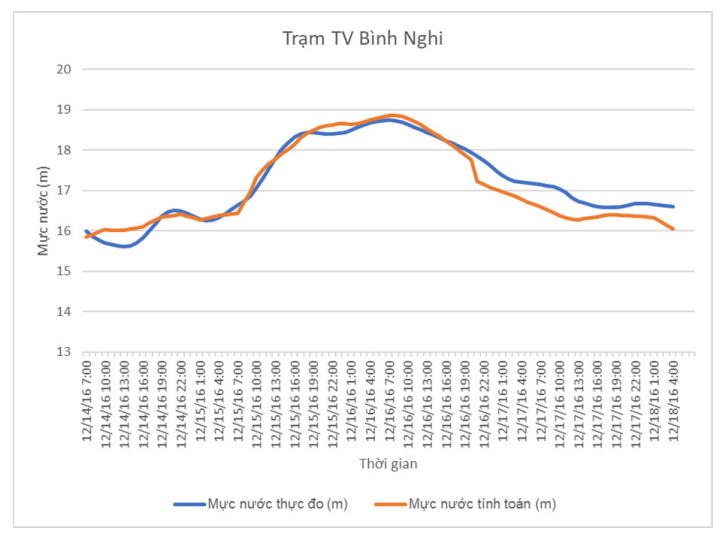

Hình 4. Đưòng quá trình mực nước tính toán và thưc đo trạm Bình Nghi năm 2016

Bảng 4. Kết quả kiểm định mô hình

\begin{tabular}{lllll}
\hline \multirow{2}{*}{ Trạm } & \multicolumn{3}{c}{ Cao trình mực nước $(\mathrm{m})$} & \multirow{2}{*}{ Nash } \\
\cline { 2 - 4 } & Lũ 2016 & Tính toán & Chênh lệch & \\
\hline Bình Tường & 18.86 & 18.74 & -0.12 & 0.91 \\
Thạnh Hòa & 9.52 & 9.66 & 0.14 & 0.94 \\
Diêu Trì & 5.95 & 6.06 & 0.11 & 0.90 \\
\hline
\end{tabular}

Khi lũ lớn tương đương hoặc lớn hơn lũ chính vụ $10 \%$ như ở kịch bản 03 và 04 , hiện tượng tràn bờ xảy ra ở tất cả các nhánh sông. Trong những trường hợp này, tổng lưu lượng qua 3 nhánh sông chỉ chiếm khoảng 72\% lượng lũ về trường ngã ba. Trong đó khoảng 40\% lượng chảy qua nhánh sông Kone. Lượng nước qua nhánh Gò Chàm khoảng $15 \%$ và khoảng $18 \%$ qua nhánh Đập Đá.

Từ kết quả tính toán ở bảng 4 cho thấy, xu thế thay đổi ở cách nhánh sông cũng không giống nhau. Khi lũ tăng lên, tỷ lê dòng chảy qua nhánh chính sông Kone có xu hướng giảm, ngược lại ở nhánh Gò Chàm tỷ lệ này lại tăng lên, trong khi đó xu thế không rõ ràng ở nhánh Đập Đá.

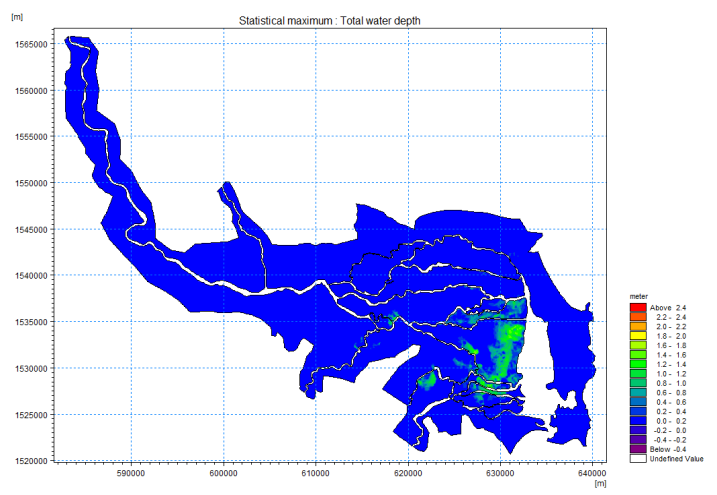

Hình 5. Mức độ ngập lụt ưng với lũ sớm, muốn $10 \%$

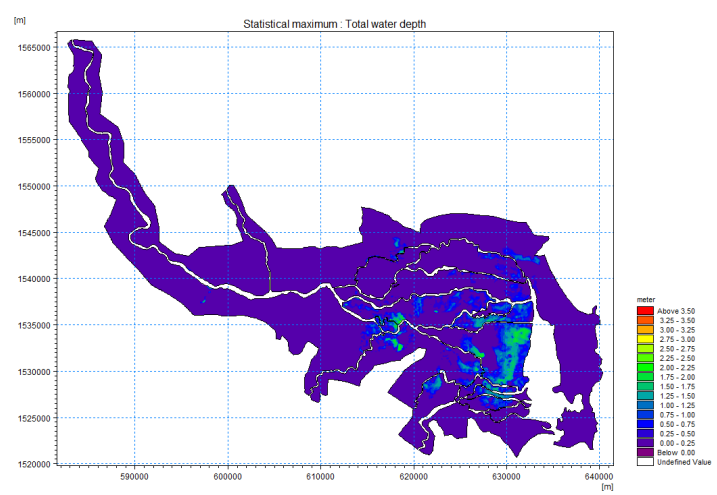

Hình 6. Mức độ ngập lụt ứng với lũ sớm, muốn $5 \%$

Bảng 5. Lưu lượng $\left(\mathrm{m}^{3} / \mathrm{s}\right)$ và tỷ lệ phân chia vào các nhánh sông

\begin{tabular}{lcccc}
\hline Kịch bản & Đập Đá & Gò Chàm & Kone & Tổng \\
\hline KB 01 & $163(20 \%)$ & $84.6(10 \%)$ & $583(70 \%)$ & $831(100 \%)$ \\
KB 02 & $386(22 \%)$ & $239(14 \%)$ & $1058(60 \%)$ & $1683(98 \%)$ \\
BB 03 & $720(19 \%)$ & $530(14 \%)$ & $1568(41 \%)$ & $2817(73 \%)$ \\
KB 04 & $776(17 \%)$ & $672(15 \%)$ & $1759(39 \%)$ & $3208(71 \%)$
\end{tabular}




\section{Kết Luận}

Nghiên cứu đã thiết lập các mô hình thủy lực cho hệ thống sông Kone - Hà Thanh. Kết quả của mô hình phù hợp với số liệu đo đạc thực tế xảy ra. Thông qua mô hình, các trận lũ ứng với 4 trận lũ ứng với tần suất thiết kế được tính toán. Kết quả cho thấy, lòng sông có khả năng tải được trận lũ sớm, muộn với tần suất $10 \%$. Đối với trận lũ sớm, lũ muộn $5 \%$ xuất hiện hiện tượng tràn bờ, tuy nhiên mức độ ngập lụt không lớn. Nghiên cứu cũng chỉ ra rằng khi lũ nhỏ không có hoặc có hiện tượng tràn bờ ít, lưu lượng qua nhánh sông Kone sau hạ lưu đập Bảy Yển chiếm từ 60 -70\% dòng chảy trên sông Kone trước phân lưu. Đối với những trận lũ lớn, tỷ lệ này giảm xuống còn khoảng 40\% trong số $72 \%$ lưu lượng chuyển trong các lòng sông.

\title{
Tài Liệu Tham Khảo
}

1. Thủ Tướng Chỉnh Phủ (2012), Quyết định Phê duyệt Quy hoạch thủy lợi khu vục miền Trung giai đoạn 2012 - 2020 và định hướng đến năm 2050 trong điều kiện biến đổi khi hậu, nuớc biển dâng 24/10/2012.

2. Denmark Hydraulic Institute (DHI) (2007), MIKE FLOOD Reference Manual DHI, 514 pp.

3. Denmark Hydraulic Institute (DHI) (2007), MIKE FLOOD User Guide DHI, 514 pp.

4. Đỗ Anh Đức, Trần Kim Châu, Nguyễn Thanh Thủy, Lê Thi Thu Hiền, (2018), Thiết lập mô hình mura rào dòng chảy phục vu công tác dụ báo lũ cho hệ thống hạ lưu sông Kone - Hà Thanh, Hôị nghị NCKHCN thường niên ĐHTL 2018.

\section{ESTIMATING THE RATE OF FLOW DISTRIBUTION INTO THE TRIBUTARIES WITH DIFFERENT FLOOD SCENARIOS AT BAY YEN JUNCTION IN KONE - HA THANH RIVER SYSTEM IN BINH DINH PROVINCE Tran Kim Chau', Do Anh Duc², Bui Manh Bang² \\ ${ }^{1}$ Thuyloi University \\ ${ }^{2}$ Vietnam Academy for Water Resources}

\begin{abstract}
Flow distribution at the confluence of rivers is a complex issue. It plays a decisive role in the hydraulic regime of the river system as well as the flood control standards in the downstream of the tributaries. In this study, the authors used hydraulic models to estimate the rate of flow distribution into the tributaries of the Kone - Ha Thanh river system at the Bay Yen junction in correspondence to the different flood scenarios. Research showed that the amount of water transferred through tributaries had a tendency to be heterogeneous as floods increase. To a major flood, the total amount of water transferred through the tributaries was only about $72 \%$ of the water coming to the junction with 40\% moving to the main stream of the Kone River. The amount of water flowing through Dap Da and Go Cham branches was $18 \%$ and $14 \%$, respectively. These values are the basis to define different flood protection standards for structures located at downstream
\end{abstract}

Keywords: Kone - Ha Thanh, flow distribution, Mike Flood, Bay Yen. 